\title{
Carl G. Jung y Edmond Cros: el espíritu de la época y el sujeto cultural*
}

Fecha de recepción: 8 de agosto de 2017

Fecha de aceptación: 9 de septiembre de 2017

\section{Resumen}

El denominado "espíritu de la época”, concepto usado por Carl G. Jung en relación a su acercamiento al arte y a la ciencia, enriquecido a su vez por el de inconsciente colectivo, guarda concordancia con la noción de sujeto cultural de Edmond Cros. A pesar de surgir en diferentes momentos históricos, Cros y Jung abordan cómo la cultura y lo simbólico -lo dado- se reproducen en toda producción social o artística -lo creado-. En este artículo se revisan las aplicaciones hechas por el psicoanalista suizo en referencia al proceso creativo y el fenómeno literario para establecer una comparación entre los postulados de ambos pensadores.

Palabras clave: sujeto cultural, cultura, espíritu de la época, Cros, Jung, sociocrítica.

Citar: Gómez Gray, A. (julio-diciembre de 2017). Carl G. Jung y Edmond Cros: el espíritu de la época y el sujeto cultural. La Palabra, (31), 77-88. doi: https://doi. org/10.19053/01218530.n31.2017.7281.

\begin{abstract}
Alana Gómez Gray
Profesora de la Asociación Cultural Impossibilia, España. Doctora en Teoría de la Literatura y del Arte y Literatura Comparada de la Universidad de Granada.

elvacioestavacio@gmail.com

* Artículo de reflexión producto de la investigación "La teoría sociocrítica crosiana y su interdisciplinariedad".
\end{abstract}




\section{la palabra \\ Carl Jung and Edmond Cros: the Spirit of the Times and the Cultural Subject}

\section{Abstract}

This paper examines the relation between the concept of "spirit of the times" used by Carl G. Jung in his approach to art and science, enriched by his concept of "collective unconscious", and the notion of "cultural subject" proposed by Edmond Cros. Even though these concepts emerge in different historical moments, both Cros and Jung approach how culture and the symbolic -what is given- are reproduced in every social and artistic production -what is created-. This article examines the developments made by the Swiss psychoanalyst in reference to the creative process and the literary phenomenon, in order to establish a comparison between the postulates of both thinkers.

Key words: cultural subject, culture, spirit of the times, Cros, Jung, Sociocriticsm.

\section{Carl G. Jung y Edmond Cros: 1'esprit du temps et le sujet culturel}

\section{Résumé}

“L'esprit du temps", concept utilisé par Carl G. Jung pour penser l'art et la science, enrichi par celui de l'inconscient collectif, est en rapport avec le concept de sujet culturel d'Edmond Cros. Bien qu'ils appartiennent à des époques différentes, Cros et Jung proposent de quelle manière la culture et le symbolique apparaissent dans toute production sociale ou artistique. Dans cet article on analyse les applications faites par Jung au processus créatif et au phénomène littéraire, pour établir une comparaison entre les énoncés des deux penseurs.

Mots-clés: sujet culturel, culture, esprit du temps, Cros, Jung, sociocritique. 
Pierrete Macuzinsky (citada en Chicharro, 2012, p. 28) calificó el quehacer de la sociocrítica como práctica transdiciplinar, en tanto que su metodología podría ser calificada como "fronteriza", es decir, por la característica de plasticidad que posee esta teoría, capaz de abordar diferentes géneros a la par de establecer un diálogo con otras disciplinas.

El propio Edmond Cros hace notar la estrecha relación entre sociocrítica y psicología, al estudiar el proceso de identificación entre el Yo y el Otro, al indagar en la dimensión individual y colectiva del sujeto (ver Cros, 2002) o en el desarrollo de la consciencia a través del lenguaje. Como es sabido, el teórico francés se nutre en particular de los postulados de Jacques Lacan para explicar cómo el ser humano emerge cual sujeto durante su niñez al acceder a la práctica discursiva, así como para "entrever la realidad bajo las diversas capas de los discursos sociales que escapan a la conciencia del sujeto" y de la que se desprenderá la idea del no-consciente. En los monólogos infantiles, queda muy claro cómo se manifiesta la impronta cultural pues la/el niña/o "no sabe lo que dice", sino que "es hablado" (Cros, 2002, p. 16) por las condiciones particulares del ámbito social, económico y político al que pertenece dentro de un espacio histórico determinado.

Al observar el campo cultural de la segunda mitad del siglo XIX y al estudiar el ideologema 'consciencia', Cros muestra cómo lo que ocurre en una esfera del saber se filtra hacia el resto. En concreto, se refiere a los cambios que hubo en los discursos de Sigmund Freud y Ferdinand de Saussure al "contaminarse" con los avances que en ese momento se daban en el área de la óptica fisiológica (Ver Cros, 2011b, 2011c). Del mismo modo, todo individuo, en cualquier lugar o periodo, verá afectado su decir -y su pensar- por el vínculo indisoluble que lo une a su sociedad y a los cambios que esta experimenta a lo largo del tiempo.

Por esta razón dinámica, a la par que opresiva, los discursos se revisten de suma importancia para la sociocrítica en tanto que es donde se hacen patentes las condiciones específicas de inserción de todo sujeto en un grupo y una ideología.

Ahora bien, este sujeto que nos ocupa, al recoger en sí lo que lo rodea y de donde surge, ya no puede ser considerado solo individual: recuérdese que, en este plano, ningún sujeto puede ejercer sobre su cultura ningún tipo de acción (Cros, 2002, p. 11) y únicamente se diferenciará de los demás en la medida en que se adecue "a los modelos de pensamiento y comportamiento que le son propuestos" (Chicharro, 2012, p. 78). Será, luego, transindividual o colectivo al estar inmerso en un ya aquí ideológico, al ser parte representativa de un universo delimitado por sus prácticas sociales. Su discurso no será otro que el de "ser hablado" y se reproducirá para la posteridad en sus productos culturales, en textos ficcionales, el cine, la música, los cómics, el folklore o las tradiciones populares, campos de información valiosa sobre los mecanismos ideológicos y económicos que subyacen en toda cultura, la cual funciona, a su vez, como "una memoria colectiva" (Cros, 2002, p. 11). El sujeto se convertirá entonces en cultural, concepto central del pensamiento crosiano que sirve para nombrar tanto al mecanismo de sujeción y subjetivación que designa "a un "yo" en tanto una instancia discursiva", para referirse a ese "sujeto colectivo en una sociedad concreta" (Moszczyńka, 2012, p. 13) como para "rendir cuenta de lo socioeconómico transcrito den- 
tro de lo cultural (Cros, 2002, p. 25). ${ }^{1}$

La sociocrítica enfatiza, ante las circunstancias que enfrenta todo individuo, cómo este reproduce la lengua de su entorno sin cuestionamiento alguno. La persona carece de la capacidad de percatarse de que se encuentra inmersa en esa lengua porque esta existe desde antes de su nacimiento, a la par no es consciente de que es el medio a través del que conocerá y representará su mundo (Cros, 2011c).

Luego, con base en las ideas saussureanas, nuestra teoría de análisis del discurso fija su atención en el uso sincrónico del lenguaje, puesto que "el sujeto se realiza y se da a conocer esencialmente por medio de los fenómenos de consciencia que se materializan a partir del momento que se tiene acceso al lenguaje" (Cros, 2011c, p. 119). Dichos fenómenos de conciencia o hechos socioidelógicos, se manifiestan como realidad en signos de manifiesto funcionamiento social (Chicharro, 2012), por ejemplo, a través de la lectura y de la escritura.

En consecuencia, es subrayable, más allá del contenido, conocer lo que el texto produce/reprodu- ce a través de aspectos discursivos, como se muestra en las microsemióticas intratextuales, por citar solo una de las herramientas de análisis sociocríticos, donde se encuentran las pautas para determinar los diferentes sujetos colectivos a los que pertenecen el o la escritora en tanto hija/o, esposa/o, ciudadana/o, trabajador/a, etc. (Cros, 2011c).

Por ende, el sujeto cultural sería cada miembro de una sociedad cuyo $Y o$ borra su contorno en contacto con las otras personas y provoca la constitución de un único individuo hecho de la colectividad. Este último, a su vez, se encuentra "atrapado en una red de signos organizada según líneas de sentido y trazados ideológicos que constituye lo que se suele designar con el nombre de cultura" (Cros, 2002, p. 18) y que, para efectos de análisis de esta última, se toma como base primordial "la problemática de la apropiación del lenguaje" (p. 19).

La cultura, por lo tanto, no es parte del inconsciente sino del no-consciente toda vez que, como afirma Goldmann y se hace eco Cros,

the no-conscious is a creation of the collective sub- ject. It is different from the Freudian unconscious by the fact that is not repressed, and it does not need overcome any resistance in order to become conscious, but can only be brought to light through scientific analysis. (Cros, 2011a, p. 37).

Sin embargo, esto no implica en realidad una toma de conciencia para la persona en sí, pues esta es "hablad[a]" por su sociedad y cultura, como ya hemos expuesto, sino que dirá "siempre más de lo que quiere decir y de lo que cree decir" (Cros, 2002, p. 17) porque hablará influida por la libertad que le provee la inconsciencia. Dicho de otro modo, se limitará a transcribir en sus expresiones lingüísticas su lugar dentro de la ideología y los valores de ese sujeto cultural del que forma parte. Externará en sus palabras lo social y lo histórico que la delimitan; ya lo exponía Emile Benveniste al afirmar que "no hay más testimonio objetivo de la identidad del sujeto que el que éste da sobre sí mismo al hablar" (citado por Cros, 2002, p. 13).

Como podemos comprobar hasta aquí, al ser el sujeto cultural por demás sustancioso en información, ha hecho que Cros

\footnotetext{
Para Cros (2002), el sujeto cultural es "una instancia que integra a todos los individuos de la misma colectividad: en efecto, su función objetiva es integrar a todos los individuos en un mismo conjunto al tiempo que los remite a sus respectivas posiciones de clase, en la medida en que [...] cada una de esas clases sociales se apropia de ese bien colectivo de maneras diversas". Asimismo, designa con ese término "1- una instancia del discurso ocupada por Yo, 2- la emergencia y el funcionamiento de una subjetividad; 3- un sujeto colectivo; 4- un proceso de sumisión ideológica" (p. 12).
} 
se haya ocupado de él con especial ahínco a lo largo de su trayectoria teórica. No solo a la sociocrítica le interesa, más allá de los aspectos de contenido, lo que queda alojado en las piezas estructurales de toda obra de creación. Esta teoría no tiene la exclusividad de querer conocer lo que es el ser humano en tanto parte y representante de una cultura -ya el estructuralismo genético aportó el concepto de sujeto transindividual-, otros pensadores se hicieron las mismas preguntas dentro del marco de sus respectivas disciplinas. Una de estas personas fue el psicoanalista Carl G. Jung, quien refería que no se puede hallar ni aprehender en las actividades humanas "la esencia del alma en sí, sino precisamente sólo sus múltiples formas aparentes" (Jung, 2007, p. 78), y se refería con "formas aparentes" a lo externo otorgado por la sociedad de pertenencia.

\section{Jung y la obra de su época}

Es nuestro objetivo acercarnos al hecho de que Jung prestó atención al aspecto social heredado y a sus reproducciones $\mathrm{y}$ manifestaciones a través de los productos culturales. Es conocido que el médico suizo reflexionó acerca del arte, la creación y el artista, de tal suerte que dedicó detallados artículos a la obra de Goethe o Joyce, por ejemplo, así como que incursionó él mismo, en calidad de aficionado, en el ejercicio de la pintura $y$ la escultura. Nos centraremos en lo que podríamos calificar como el atisbamiento de Jung al sujeto cultural de su época. No se trata de un postulado psicológico, sino que en sus estudios sobre la obra artística reconoce el trasfondo que deja en ella la ideología del momento.

Jung (2000) considera los valores del espíritu de la época determinantes en la elaboración racional, al examinar la controversia de la transubstanciación de Cristo entre el abad Pascasio Radberto y el filósofo Escoto Eriúgena (p. 46), o en el trabajo de Friedrich Schiller sobre los tipos psicológicos (pp.95-165).

El escrito del siglo IX de Radberto, en el que establece que en la eucaristía el vino y la hostia se transforman en la sangre y carne reales de Cristo, se convierte en dogma. No obstante, a Escoto Eriúgena, neoplatónico defensor de la idea de que la razón debía prevalecer, siempre se le ha tomado como adelantado a su época. Un ejemplo singular es que él no participaba del sentir de sus conciudadanos, pues estaba convencido de que la eucaristía era una simple conmemoración de la última cena. Sin citar fuentes, Jung afirma que fue asesinado por los monjes de su propio claustro a causa de su discrepancia teológica.

Por su parte, la Revolución Francesa deja su huella en Schiller, en especial en su Sobre la educación estética del hombre, publicada en 1826, donde diserta acerca de cómo no van a la par la cultura individual y la cultura colectiva, la representación y desarrollo como individuos únicos y como seres colectivos. El alemán realiza su análisis con presupuestos del intelectualismo racionalista, lo que, para Jung, se corresponde con el pensamiento en boga en esos días y, por eso mismo, en motivo de algunas equivocaciones en la percepción y solución del conflicto.

Nos detendremos, sin embargo, en lo relativo al espíritu de la época en la obra de arte. Por su afán de conocimiento de los asuntos del alma y por "encontrar la verdad", Jung amplió su campo de estudio hacia áreas de común menos transitadas por su especialidad y centró su atención en explicar psicológicamente la obra de arte y el fenómeno literario.

Al ser devoto lector de Goethe y de Schiller, no asombra su preferencia por la poesía y la novela. Es de común conocimiento el enfoque de Freud de explicar la obra artística a partir de las vivencias personales del/a creador/a, no obstante, Jung se posicionó en contra. Para el suizo, remitirse antes que nada a las psicosis propias de la infancia o de la sexualidad del artista como piezas clave para la comprensión de su narrativa o pintura, equivalía no solo a 
poner en el mismo plano obra y neurosis o a la escritor/a con cualquier otra persona con perturbaciones patológicas -todo mundo las padece en mayor o menor grado-, sino también en tratar a la obra como si fuera una enfermedad. La vinculación de las particularidades de cualquier pieza literaria o pictórica con las peculiaridades íntimas de su creador/a se traduce en un alejamiento de la obra de arte para caer "en un laberíntico y confuso entramado de condicionantes psíquicos, convirtiéndose el artista en un caso clínico y eventualmente en el enésimo ejemplo de psychopathiasexualis" ( Jung 2007, p. 60).

Al ser suprapersonal, la obra de arte y no tener cabida las limitaciones personales ni las vulgaridades cotidianas del o la poeta, el enfoque para Jung estaría más bien en el proceso creador, entendido como el debate del/la artista entre su propia consciencia y la guía de lo inconsciente, entre su voluntad y lo heredado. A lo largo del tiempo, ha quedado demostrado que toda obra puede llegar a trascender el entendimiento consciente y acercarse a aquello que "no ha sido reprimido ni olvidado", es decir, al inconsciente colectivo, que "no existe en sí mismo, ya que no es más que una posibilidad que hemos heredado de tiempos inmemoriales en forma de imágenes mnémicas $\mathrm{o}$, en términos anatómicos, en nuestra estructura cerebral" (Jung, 2007, p. 72).

El inconsciente colectivo sobrepasa la conciencia contemporánea, es lo emparentado con lo arquetípico, es decir, con todo aquello que es bien común de las sociedades humanas con indiferencia del lugar o el sitio: ahí encontramos el círculo, la madre o el sabio. El ser humano “está siempre y en todas partes bajo el influjo de representaciones dominantes" (Jung, 2015, p. 58) que lo afectan no solo en sus acciones, pensamientos y habla, sino incluso en el plano interior, pues "cuanto mayor es la carga de la conciencia colectiva tanto más pierde el yo su significación práctica" (p. 164). Pero, en la obra de arte se inserta, además de lo simbólico, ${ }^{2}$ también lo social inmediato.

Al hacer referencia al proceso impersonal o complejo autóno$\mathrm{mo}^{3}$ por el que atraviesa todo creador, Jung se remite así a las condiciones sociohistóricas que conviven con el o la artista en su papel de ser colectivo, es decir, "portador y conformador del alma inconsciente de la humanidad" (Jung, 2007, p. 94) y conviven en él/ella lo inmediato y lo trascendental. Además, de la misma manera que en la o el poeta "se colman las necesidades anímicas del pueblo" (p. 96), es de ese pueblo que recibe a su vez "el eco de la vida diurna” (p. 84), el material con el cual trabajará en su obra.

Jung recurre a la expresión hegeliana para referirse a lo esencial de todo periodo histórico, espíritu de la época (Zeitgeist), para designar aquello que rodea al artista en tanto su sociedad $\mathrm{y}$ el momento en que vive, los márgenes dentro de los que actúa, piensa y siente, lo impuesto por lo inmediato que lo rodea y por el grupo del que surge. Poderoso espíritu ante el que el creador "no tiene ninguna posibilidad de apoderarse de un punto arquimédico ajeno a su mundo con el que fuera posible elevarse por encima de su consciencia contemporánea" (p. 68).

Desde su psicología analítica, Jung ve la época en relación con el inconsciente colectivo su objeto esencial de investigación-, y le reconoce unas fuerza e identidad insoslayables que lo llevan a estampar su huella profunda en cada uno de los actos del ser humano:

Cada época tiene su unilateralidad, su prevención y su padecer anímico. Una época es como un alma

2 Jung (2011) define al símbolo como "la mejor descripción y formulación posible de un objeto no cognoscible íntegramente" (p. 136)

3 Nombre con el que se designa al hecho de que el proceso creador es "como un ser vivo implantado en el alma" del ser humano (Jung, 2007, p. 67). 
individual, presenta su peculiar y limitada disposición consciente y necesita por ello una compensación que lo inconsciente colectivo propicia al confiar a un creador o a un visionario la expresión de lo innombrado en la disposición de la época y que conjura, en hecho o imagen, lo que la necesidad incomprendida de todos esperaba, ya sea bueno o malo, para la sanación o la destrucción de una época (Jung, 2007, p. 91).

Toda vez que el inconsciente colectivo, "esfera de la mitología inconsciente cuyas imágenes primigenias constituyen un bien común de la humanidad" (p. 72), está unido al espíritu de la época, se da un proceso de ida y vuelta pues "acaece un acto creador que tiene que ver con la época entera" (p. 90). Lo inconsciente -simbólico y sociohistórico- se hace patente en los signos; por tanto, aunque el artista tenga la idea de que su producción parte de una intencionalidad propia y libre, sería esta creencia una mera ilusión ya que sus aquí y ahora han puesto sus límites en su consciencia, a la par que los arquetipos surgirán sin que ejerza control alguno sobre ellos.
De este modo, el ser humano se debate a lo largo de su vida entre el inconsciente colectivo y el espíritu de la época, entre esa información universal innata más la información específica del sitio y cultura donde se ha nacido y crecido; toda vez que la primera esfera se encuentra vinculada con lo simbólico, ${ }^{4}$ es la segunda, la de base histórica, la que nos interesa por su relación con la sociocrítica al determinar cómo, verbigracia la lengua y el lenguaje conforman una parte esencial del quehacer colectivo al transmitir y desarrollar "verdades generalmente reconocidas" (Jung, 2015, p. 163) así como la manera de condicionar y estructurar el conocimiento (Cros, 2011c, p. 121). El psicólogo deja constancia a lo largo de sus obras que el lenguaje es un punto de partida básico para la interpretación. ${ }^{5}$

Ahora bien, aunque los arquetipos "no se difunden meramente por la tradición, el lenguaje o la migración, sino que pueden volver a surgir espontáneamente en toda época y lugar sin ser influidos por ninguna transmisión exterior" (Jung, 2007, p. 73), este surgir o desaparecer pareciera estar condicionado por el espíritu de la época. En efecto, cada sociedad otorga atención o no a tal o cual símbolo así como que su uso y su lectura-que no su significado-dependerá tanto del desarrollo de las conciencias personal y colectiva como de lo cultural vigente. Jung pone por muestra que, en su tiempo, el águila de Zeus se había transfigurado en avión o el héroe matadragones en tenor de ópera. Del mismo modo, dicha entidad abstracta afecta tanto al emisor como al receptor de la obra de arte: "el lector tampoco va más allá de los límites impuestos a la consciencia del autor por el espíritu de la época" (p. 68). Mas, al igual que demarca, abre horizontes: cuando se relee a alguna poeta y se le encuentran aspectos nuevos, "lo que ahora descubrimos en su obra ya estaba ahí antes, pero constituía un símbolo oculto cuyo reconocimiento sólo nos es accesible gracias a la renovación del espíritu de la época" (p. 69).

En suma, en toda sociedad cambia, a lo largo de su historia, la aprehensión de los contenidos de los productos culturales. Jung (2007) pone por muestra Fausto, de Goethe 2007), al plantearse la eventualidad de la relación de su contenido con los rasgos del periodo del que surge, al mismo tiempo que enfatiza su carácter de recomendación atemporal a la conciencia de la colectividad:

La gran poesía, que bebe del alma de la humanidad, no se explicaría en

\footnotetext{
$4 \quad$ Cros define al lenguaje simbólico como "esta institución social que el ser humano ha desarrollado a lo largo de su evolución y que es el germen de su constitución progresiva y evolutiva de lo que solemos llamar conciencia" (Cros, 2011, p. 118).

5 Son auténticos estudios filológicos sus observaciones sobre la palabra idea (2015), el sí mismo o el pez (cfr. 2011).
} 
mi opinión correctamente si se quisiera remitir a lo personal. Pues allí donde lo inconsciente colectivo se funde con la consciencia de la época, acaece un acto creador que tiene que ver con la época entera, pues la obra constituye entonces, en el sentido más profundo, un mensaje para los contemporáneos. ( $\mathrm{p}$. 90 , el subrayado es nuestro).

El pensador suizo creía con tal intensidad en el peso de la época en la obra artística, que llega a preguntarse si esta tragedia podría haber sido escrita por alguien que no hubiese nacido $\mathrm{y}$ crecido en Alemania. Del mismo modo, juzgaba que el anuncio de Nietzsche de la muerte de Dios respondía a las mutaciones que acaecían en la conciencia de la sociedad en esos instantes. En este sentido, para Jung las grandes obras literarias gozan de una identidad profética, al menos así calificaba al Prometeo paciente del olvidado Nobel Carl Spitteler, al tocar el tema de moda, el del debate entre aceptar la fuerza del destino o creer que el ser humano ejerce su propia voluntad ante lo ominoso.

Otra novela a la que Jung (2007) dedicó un ensayo literario fue al Ulises de Joyce por constituir para él un documento humano "esencial y característico de nuestra época" (p. 99). En ese texto publicado en 1932, el analista expone lo que encontraba en su paso por la lectura de la obra joyceana y se asombra al descubrir que, como ninguna otra, en ella prima la razón del escritor antes que el inconsciente colectivo. Se trata de un libro en el que el carácter simbólico no existe, afirma, en el que pareciera incluso haber una intencionalidad en apartarse de cualquier trasfondo arquetípico. Lo que conforma su núcleo no es otro elemento que el vacío, el "absolutamente desesperanzado", el insoportable, el "que ahoga y deja sin resuello" (p. 100).

El psicoanalista lector halla en el escritor irlandés, lo positivo de romper con las expectativas habituales de agradar en "la tendencia a enajenar la realidad, o bien, -a la inversa- a enajenarse de la realidad" propia de "la descomposición originaria de la personalidad en fragmentos" (p. 107) provocada tanto por la época como por la historia de su tierra natal. La recepción de la obra, como no podría ser de otra forma, a pesar de su génesis local, atrae a todo mundo. El suizo escribe que, tal vez, su éxito en el año de su publicación se debió a que "convenía a sus coetáneos":

el libro debe de decirles algo, o incluso revelarles algo que antes no sabían o no sentían. [...] debe de haber casi clases de po- blación que, como el Ulises, están tan aferradas a un enclave espiritual que se precisa la dinamita joyceana para quebrar su hermético aislamiento. Estoy convencido de que así es: seguimos inmersos en la Edad Media. No tiene vuelta de hoja. Por eso se necesitan profetas negativos como Joyce (o Freud) para aclarar a los medievales y extremadamente prejuiciosos contemporáneos lo "también real". (p. 110).

Esta cita nos permite advertir que, en el ser humano hay patrones de conducta ancestrales, cómo el sujeto cultural se mantiene casi idéntico a lo largo del tiempo. Dado que lo socioeconómico está transcrito en lo cultural y es posible encontrar sociedades actuales en las que convivan sistemas económicos como el capitalismo más avanzado con otros más primitivos como el trueque, del mismo modo Jung se desesperaba porque "la humanidad no sea uniforme sino que esté formada por individuos cuyas condiciones espirituales están dispersas en un periodo de por lo menos diez mil años" (Jung, 2005, p. 32).

No obstante, ni el espíritu que nombra Jung ni el sujeto colectivo de Cros son fenómenos estáticos. A través de las excepciones encarnadas en artistas o pensadores, la conciencia se 
suelta un poco y, entonces, se modifica con levedad la cultura.

El psicoanalista creía que el temor ante la superstición y la "ilustración materialista" que imperaban cuando él vivía eran una invención de la época, "un producto evolucionado de la primitiva magia y temor a los espíritus" (Jung, 2007, p. 88). Ni espíritu ni sujeto son en exclusiva de índole negativa, toda vez que al contacto con el Otro se fomenta el aprovechamiento de la potencialidad humana, plasmada sobre todo en los productos culturales. Cuando estos últimos se insertan en el espacio de lo literario, "donde operan a la vez mediaciones de lenguaje y mediaciones institucionales" (Cros, 2009, p. 85), por surgir bajo el mandato de una ideología, asumen un carácter educativo además del intrínseco adoctrinador.

No solo la literatura sino el arte en general, "convoca a esas figuras que más faltan al espíritu de la época" por su contacto con el inconsciente colectivo (Jung, 2007, p. 74). Cualquier persona entregada a la creación será una especie de médium de las herencias social y primigenia, y con esa cualidad de intérprete contribuirá a "compensar del modo más eficaz las carencias y las unilateralidad del espíritu de la época" (p. 74). Aunque, de forma paradójica, es en concreto ese entregarse a la creación lo que abriría variantes en la alie- nación ideológica. Ya hemos mencionado con Cros que nadie es capaz de ejercer sobre su cultura ningún tipo de acción, pero sí cabe la posibilidad de diferenciarse de los demás en la medida de la adaptación a lo que el sujeto cultural propone. Cuando el o la poeta cede a su anhelo, dice Jung, se desvía de la norma y encuentra lo que falta a los demás y se convierte así en la "educador[a] de su época" (p. 74) en tanto que abastece a su sociedad de aquello desconocido que precisa en ese momento, tal cual le parecía que hizo Joyce.

Además, no puede pasarse por alto que el psicólogo mismo vio afectada su propia teoría por lo que se pensaba y creía en el mundo cuando llevaba a cabo sus análisis y reflexiones. Nos referimos a su postura hacia las mujeres, pues su delineación responde a la fabricación social que se hizo de nosotras de los siglos XVII a XIX. Como no puede ser de otra manera, su teoría misma se ha vuelto obsoleta en lo relativo a la psique femenina, debido a afirmaciones tan enojosas como esta:

En los varones está por lo general más desarrollado el logos que el eros, función relacionante. En la mujer, al contrario, el eros constituye una expresión de su verdadera naturaleza, mientras que su logos, no rara vez representa un lamentable accidente, que suscita malentendidos e interpretaciones irritadas en el círculo de la familia o de los amigos, porque no consiste en reflexiones sino en opiniones. (Jung 2011, p. 39).

Es evidente que nunca se interesó por Mary Wollstonecraft o de Olympe de Gouges, además, recordemos que Suiza fue el último país europeo en acceder al sufragio femenino (1971), con lo cual se comprueba el hecho de que es el exterior lo que determina de forma implacable el hacer individual.

\section{Reflexiones finales}

Nos hemos acercado de forma breve al fenómeno literario y al proceso creativo de la mano del mayor exponente de la psicología analítica, y hemos constatado que los productos culturales se ven condicionados $-\mathrm{O}$ son producto- por el acontecer que los rodea. Que cualquier expresión del ser humano estará siempre dentro de los límites de su cultura, pues "el sujeto no se identifica con el modelo cultural, al contrario; es ese modelo cultural lo que lo hace emerger como sujeto" (Cros, 2002, p. 20).

Encontramos, por lo tanto, correspondencia entre el postulado crosiano de sujeto cultural y la denominación espíritu de la época hecha por Jung. Hay fra- 
ses de cada uno de estos teóricos que asombran por su similitud: Cros afirma que "el sujeto dice siempre más de lo que quiere decir y de lo que cree decir" (Cros, 2009, p. 159) y Jung, que "el autor dice, abierta o encubiertamente, más de lo que cree decir, más de lo que él mismo percibe" (Jung, 2007, p. 66) y el artista "cree hablar de sí, pero el espíritu de la época es quien dicta sus palabras, y lo que éste dice es, pues actúa" (p. 112).

Cros hace suyas las palabras de Bajtín "no es la expresión la que se adapta a nuestro mundo interior sino más bien nuestro mundo interior el que se adapta a las posibilidades de nuestra expresión, a sus vías y orientaciones posibles" (Cros, 2011c, p. 114), mientras que Jung sostiene que el ser humano "emplea la palabra hablada o escrita para expresar el significado de lo que desea transmitir" (Jung, 1995, p. 20). La cuestión radical es quién habla a través del sujeto hablante y cómo.

Jung dedujo que el grado de fantasía $^{6}$ habitual en cada periodo de la historia está condicionado por el nivel de racionalismo que prevalezca en él, es decir, qué tanto es tabú para la ciencia; dedujo también que en Joyce hablaba la vacuidad de la época, la fragmentación del individuo; y en Nietzsche, la inhumanidad del "hombre fáustico". Del mismo modo, en el propio Jung hablaban el patriarcalismo y el fantasma de las guerras mundiales. Años más adelante, alguien podrá deducir lo que habla en Cros.

Por consiguiente, este "ser hablado" está intrínsecamente relacionado con la consciencia, entendida por Cros como:

un universo semiótico de representaciones propias del sujeto, que nace a sí mismo y a la mirada intersubjetiva por mediación de la imagen percibida. La configuración de este universo es producto de una actividad de transmisión y de adaptación a los modelos socioculturales del entorno. (Cros, 2009, p. 154).

La consciencia no es algo preexistente sino un hecho socioideológico que se conforma con base tanto en las prácticas sociales e institucionales como en la relación con el Otro. A propósito de una exposición de Pablo Picasso en la Kunsthaus de Zurich, Jung (2007) escribió en 1932 que la conciencia "contiene reproducciones de los objetos generalmente visibles que necesariamente han de aparecerse tal como lo exigen las expectativas generales" (p. 126).
Asimismo, lo exterior es la imagen percibida, es el Otro que permite la identificación de sí misma/o en un juego dialéctico que, a su vez, es la identificación del Otro consigo misma/o. Ese Otro, a decir de Lacan, es el objetivo al pronunciar la palabra. Mas, ese Otro es simultáneamente inalcanzable o irrepresentable, complementa Cros, puesto que dicha identificación solo puede hacerse a través de los propios modelos discursivos conformados por los medios socioculturales del entorno.

De ahí que, las situaciones "típicas", aquellas que se repiten una y otra vez en cada sociedad sean tan gratas a todos sus miembros, se trate de rituales religiosos, fiestas tradicionales o bestsellers. La razón del disfrute radica en que "en esos instantes ya no somos seres aislados, sino especie, la voz de la humanidad entera se alza en nosotros", explica Jung (2007, p. 73). "El sujeto cultural, de naturaleza doxológica, legisla, dicta pautas de conducta, designa paradigmas, recuerda verdades basadas en la experiencia o en la fe", escribe Cros (2002, p. 19).

Sin embargo, por más que todo individuo sea capaz de asimilar "sucesivamente elementos semiótico-ideológicos variados, heterogéneos y contradictorios que le van proponiendo las di-

$\overline{6} \quad$ Entendida esta "tanto como pensamiento como sentimiento, es tanto intuición como sensación" (Jung, 2000, p. 76). 
ferentes comunidades (sujetos transindividuales), prácticas e instituciones por las cuales cruza" (Cros, 2002, p. 25), muchos de los productos nacidos de esa adaptación diferente de algún/a creador/a al sujeto cultural sean rechazados por el gran público, sin importar que equivalgan a lo que podría calificarse como una "mejora" colectiva.

Es incontestable que cuanto más estrecha es la relación entre inconsciente colectivo y sujeto cultural, más se tocará lo realmente humano y en él lo histórico. Así explica Jung que Fausto o La divina comedia sean imperecederas y atrapen por igual a gente de cualquier latitud, aunque en muchísima menor medida que una canción de moda llena de sintagmas fijos y clichés.

Llegamos así a concluir lo obvio, que la preocupación por quién y qué es el ser humano en su relación con las fuerzas sociales que lo delinean, cruza todos los momentos históricos $\mathrm{y}$ las doctrinas, tal cual podemos ver en las similitudes entre Jung y Cros. La cuestión es cómo se historiza tal preocupación. Aunque trabajan con nociones análogas, la visión dialéctica y amplia de Jung parte del idealismo objetivo propio del esencialis- mo hegeliano, mientras que la postura de Cros se sitúa en el materialismo histórico, pero ambas aterrizan en el discurso como objeto de estudio.

La sociocrítica, como ya se ha indicado, se ayuda del psicoanálisis para entender los procesos de lenguaje y constitución del sujeto. Esta trandisciplinariedad le otorga una apertura de miras que puede contribuir aún más a desentrañar esa banda de Moebius que es el sujeto cultural, que solo consiente el conocer las circunstancias sociohistóricas de la adquisición y de la constitución del material semiótico, así como su organización formal (Cros, 2009, p. 171), pero no al sujeto en sí ni a este conocer al Otro.

Si a estas condiciones particulares del devenir humano se suma la turbadora separación que existe entre el cuerpo que se siente y el que se proyecta ( $\mathrm{p}$. 175), surge la pregunta legítima de qué es, en consecuencia, lo que se conoce en realidad, qué es aquello de lo que se es consciente.

Una respuesta a esta cuestión inquietante es posible encontrarla en la literatura -huella estético-verbal permanente e indeleble del ser humano en sociedad-: a través del arte de la palabra hablada y escrita, es factible al individuo atisbar los mecanismos con los cuales se conforma la consciencia de su identidad. Asimismo, ya que la identificación con el Otro solo es dable a través de los propios modelos discursivos, producidos para expresar lo que se es, lo que se sabe o lo que se imagina, la poesía llega a convertirse en instrumento valiosísimo de conocimiento. Schiller (citado por Jung, 2000) afirmaba que

todos los poetas que lo sean realmente pertenecerán a los ingenuos o a los sentimentales, según la naturaleza de la época en que florezcan y según las circunstancias accidentales que ejerzan influencia sobre su cultura general o sobre su pasajero temple de ánimo. (p. 160, el subrayado es nuestro).

Aunque la época actual esté regida por los avances tecnológicos y pareciera que el sujeto cultural apunta hacia la violencia, el desplazamiento y el individualismo egoísta, el florecimiento de la poesía, la lectura de Cervantes o de Dante no cesan. 


\section{Referencias}

Chicharro, A. (2012). Entre lo dado y lo creado. Una aproximación a los estudios sociocríticos. Varsovia: Universidad de Varsovia.

Cros, E. (2002). El sujeto cultural: sociocrítica y psicoanálisis. Montpellier: Éditions du CERS.

Cros, E. (2009). La sociocritica. Madrid, Arco/Libros.

Cros, E. (2011a). Towards a sociocritical theory of the text. Sociocriticism, 26(1-2), 31-47.

Cros, E. (2011b). El campo cultural de la segunda mitad del siglo XIX y su articulación con la historia (Freud, Saussure, poética, pintura abstracta). Sociocriticism, 26(1-2), 69-109.

Cros, E. (2011c). Consciencia y sociocrítica. Sociocriticism, 26(1-2), 111-123.

Jung, C. G. (2000). Tipos psicológicos. Barcelona: Sudamericana.

Jung, C. G. (2005). Psicología y alquimia. Madrid: Trotta.

Jung, C. G. (2007). Sobre el fenómeno del espíritu en el arte y en la ciencia (vol. 15). Madrid: Trotta.

Jung, C. G. (2011). Aion. Contribuciones a los simbolismos del sí-mismo. Barcelona: Paidós.

Jung, C. G. (2015). Arquetipos e inconsciente colectivo. Barcelona: Paidós.

Jung, C. G., Franz, M. L. von, Henderson, J. L., Jacobi, J., \& Jaffé, A. (1995). El hombre y sus símbolos. Barcelona: Paidós.

Moszczyńska, K. (2012). Prólogo. En: Chicharro, A. (2012), Entre lo dado y lo creado. Una aproximación a los estudios sociocríticos (pp. 11-15). Varsovia: Universidad de Varsovia. 